\title{
Trend in Viewing Quantitative Analysis as a Primary Function Involving Decision Making in Organisations
}

\author{
Karibo Benaiah Bagshaw, Kalio Linda Nissi \\ Department of Management, Faculty of Management Sciences, Rivers State University, Port Harcourt, Nigeria \\ Email: Amadi.nissi@ust.edu.ng
}

How to cite this paper: Bagshaw, K.B. and Nissi, K.L. (2019) Trend in Viewing Quantitative Analysis as a Primary Function Involving Decision Making in Organisations. American Journal of Industrial and Business Management, 9, 1492-1505.

https://doi.org/10.4236/ajibm.2019.96099

Received: May 15, 2019

Accepted: June 27, 2019

Published: June 30, 2019

Copyright () 2019 by author(s) and Scientific Research Publishing Inc. This work is licensed under the Creative Commons Attribution International License (CC BY 4.0). http://creativecommons.org/licenses/by/4.0/

\begin{abstract}
This paper is to help view the trend in quantitative analysis as a primary function that involves decision making at every level in the organisation. The study involved the identification of recent trends in quantitative analysis, quantitative analysis as a primary function and its impact on decision making in the organisation. Quantitative analysis is an effective tool for statistical methods, e.g. big data analysis, machine learning, network analysis, operational analysis, etc. These analysis aids decision that is made within the confines of the organisation and its environment. The times are changing with a high rate of varieties in quantitative analytical trends. It has become imperative to follow these trends for enhanced decision making in today's contemporary organisation.
\end{abstract}

\section{Keywords}

Trend, Quantitative Analysis, Decision Making

\section{Introduction}

Decision-making process involves proper and efficient implementation of strategic plans and methods to achieve desired business objective [1]. According to Dunn [2], he posits that organisational challenges and problems are interdependent, subjective, artificial and dynamic. Challenges and problems can be rarely separated into independent, discrete and, mutually exclusive parts. Quantitative analysis (mathematical techniques) provides diversity of knowledge. A manager's level of education and technical know-how of quantitative methods will help to boost the decision-making process of the organisation.

The manager's concentration with respect to decision making is centred on 
quantitative approach which is utilised via mathematical expressions describing objectives, constraints and other relationships that exist around a problem [3]. Quantitative tools are vital prerequisites for solid and effective decision-making process. Managers, who make a decision, must enhance their decision-making skills, capabilities and competence by learning and understanding the various techniques that are involved (psycho-technical).

The psychological use of information embodied in decision-making method is sometimes intermingled with the practical and technical existence of data. How decisions are made in organisations to a large extent shows problem-solving skill of such organisation. There are quantitative measures to help us choose the best fit with respect to choices in the problems or challenges encountered. Quantitative measures such as network analysis, games theory, transportation model, optimisation, regression analysis, and correlation analysis aid adequate managerial decision making. No one goes into business with problems at the back of their mind and as much as they can, it should be avoided; though we do not envisage these problems in making some decisions to move the organisation forward we encounter some problems. Quantitative analysis is an effective managerial tool that often times is neglected, relegated and delegated: managers must understand that in order to make a decision that keeps the business flying, quantitative measures are a prerequisite in carrying out certain function and making certain choices and decisions. These quantitative measures cover cost and profit analysis involving product costing, budgeting, purchasing, insurance, planning, remuneration, investments, and savings. Understand that proper application of relevant analytical tools can ensure an organisation's success when proper decisions are made. This paper is a theoretical review on the recent quantitative analytical trends involving decision making in any organisation and to add to existing knowledge

\section{Literature Review}

\subsection{Concept of Quantitative Analysis}

Quantitative analysis is numerically based; it is counted with findings that are generalizable. QA simplifies the reality in the effort to provide hard, objective, numeric data. According to [4], quantitative analyses are very essential in managerial decision-making for efficient and effective use of available resources for the growth and development of an organisation. Quantitative analysis is a process of practical problem solving based on scientific rationality. It is an application of scientific method in the study of complex systems seeking to produce an understanding of problems and to develop a model to enable the consequences of decision to be investigated. Quantitative analysis is a number of techniques with a common scientific approach which includes:

1) Linear programming,

2) Queuing,

3) Inventory control, 
4) Network analysis,

5) Correlation Analysis,

6) Regression Analysis, etc.

\subsubsection{Linear Programming}

Also known as Mathematical Optimization is a unique case of mathematical programming. It is a technique to obtain the most advantageous outcome which is usually maximum profit or lowest cost of production, in a mathematical model whose needs are shown by linear relationships. Linear programming more formally can be said to be a method for the design and operation of a system or process to make it as good as possible in some defined sense which is usually linear objective function, conditioned to linear equality and linear inequality constraints [5]. Linear programming is a commonly accustomed field of optimization for many purposes. Several applicable issues in operations research can be stated as linear programming problems. Basic unique cases of linear programming, such as network flow issues are seen as important to have begotten much research on unique algorithms for their solution. Other types of optimization issues have a number of algorithms for finding solutions for linear programming problems as sub-problems. Main concepts of optimization theory such as duality, decomposition, convexity are also inspired by linear programming. Formation of Microeconomics earlier was heavily linked with linear programming and is recently used in company management, such as planning, production, transportation, technology and other issues. However, the recent management concerns are ever-changing, most companies would like to maximize profit or minimize cost with limited resources. Thus, many issues can be seen as linear programming [6].

\subsubsection{Inventory Control}

This involves giving unchanged attention towards the Production, Sales, Maintenance, etc. with least stock. It is a mandatory aspect for the development and growth of company. Stores index is the core of a firm inventory control or stock control can be largely said as "the duty of inspecting a shop's stock. More directly, inventory control may refer to: In operations management, logistics and supply chain management, the programmed software necessary for managing inventory. It involves stock control, regulating and maximizing one's company inventory [7]. The main aim of inventory control is to highest profits with the least minimum inventory investment, without affecting customer satisfaction rate. It also involves having knowledge of where all your stock is and ensuring everything is accounted for at any given time.

\subsubsection{Network Analysis}

Is a set of unique analytical methods that are used in issues where it is mandatory to optimize and analyse a network of associated and anastomosed parts that have some connection between one another e.g. project management, where the parts are key activities of the project in the mutual time association. Another use 
of network analysis is in the field of transportation and logistics, where the components stand for the center and the dependencies are figuratively temporal or spatial. Network analysis techniques are focused on critical path optimizing or calculating between the elements [4]. These techniques are related to the notion of a network diagram, which is a perspective of the project as a diagram which introduces many links between the project activities.

\subsubsection{Queuing Model}

Mathematical examination of waiting lines or queues is the focus of queening model. Predictability of waiting time and queue lengths are one of the main goals of constructing a queuing model. Queuing theory is commonly seen as a branch of operations research due to the facts that results are most times used when making business decisions about the resources needed to provide a service [8].

\subsubsection{Regression Analysis}

In statistical modeling, regression analysis is a set of statistical method for appraising the association among variables. It includes many processes for examining and modelling variously changeable, when the attention is on the association between a dependent variable and one or more predictors (independent variables). Concisely, regression analysis aids one understands how the particular value of the criterion variable (dependent variable) reacts when any one of the independent variables is changed, while the other independent variables are left unchanged [9].

\subsubsection{Correlation Analysis}

Correlation analysis is an approach of statistical assessment applied to explain the potency of an association between two, numerically ascertained, continuous variables (e.g. height and weight). This specific type of analysis is important when a researcher needs to identify if there is a possible association between variables [9]. It is most times misunderstood that correlation analysis figures out cause and effect; in contrast, this is not the issue due to changeable that are not particularly present in the research that may have an effect on the results.

\subsection{Concept Decision Making}

Decision making is a fundamental management resource, especially in the face of complexity and dynamism requiring precision in decision making. The decision-making ability of every manager and those in spheres of leadership in organisations must be sharpened in order to face the challenges efficiently and effectively. Decision making is in business is a managerial function involving the best choice from an alternative pool of choices: Managers are referred to as decision makers. Decisions are said to be effective when it achieves zero defect, positively affecting the organisational goals and objectives [10]. In other to thrive in today's business world where the market is demand-driven and competition is high. Globalisation is putting so much pressure on management to make deci- 
sions. After the war, many of these team members continued their research on quantitative approaches to decisionmaking, leading to the growth and use of management science in non-military applications such as healthcare, manufacturing, engineering projects, transport and traffic studies, communication, business and educational administration. Decision making also involves choices among alternative courses of action as earlier defined but it also covers inaction and management is decision making though decisions made by managers sometimes in the organisation fail [11] [12] [13]. Effective decision making is an important part in maximizing effectiveness and efficiency at the workplace. Hence, decision-making became the heart of the management/administrative process [14]. Decision-making is an essential process in organizational effectiveness. Risk taking cannot be neglected or denied in decision making, for the everyday choices are made, it is accompanied with risk. Risk associated with personal decision making cannot be equated with that of the organisation especially large organisations; the risk is enormous.

Organisations need to make good choices that will affect profitability, development and continuity, it imperative that they calculate and manage the risks associated with their choices using available statistical and highly sophisticated tools. Risks in years past were considered mostly in games but today, it has gone beyond the game for leisure; it can be viewed as a theory of games needful in making the right decision for well-calculated risks.

The decision-making process in an organisation is a decision of choice from two or more alternatives involving the optimum decision of the various alternatives. The decision making is divided into the problem identification stage and the problem-solving stage [15].

\subsubsection{Model of Decision Making Process}

The above (Figure 1) diagrams depict the relationship and connectivity in the decision-making process required for organisations to thrive. Daft [15] explains it further.

a) The problem identification stage-according to Daft [16], this stage involves having information about the environment and the organization itself in assessing her performance and to note areas of failure.

b) The problem-solving stage-this is the actual process of decision making. It involves the choice of action from alternative actions or strategies and its implementation. He categorized organizations' decisions as programmed and non-programmed. Programmed decisions are identified procedures to solution finding and resolving established problems and are iterative. The decision environments somewhat sure are usually termed to be structured. Notwithstanding, non-programmed decisions can be said to be uncertain or dangerous and do have unclear environment. Many of such non-programmed decisions imply carefully structured planning due to high intensity of competitiveness in decision environment and the unsure nature of the decision outcome [15].

The business environment is in a realm of dynamism with rise in intricacy and unpredictability and still, the business manager is required to wallow 


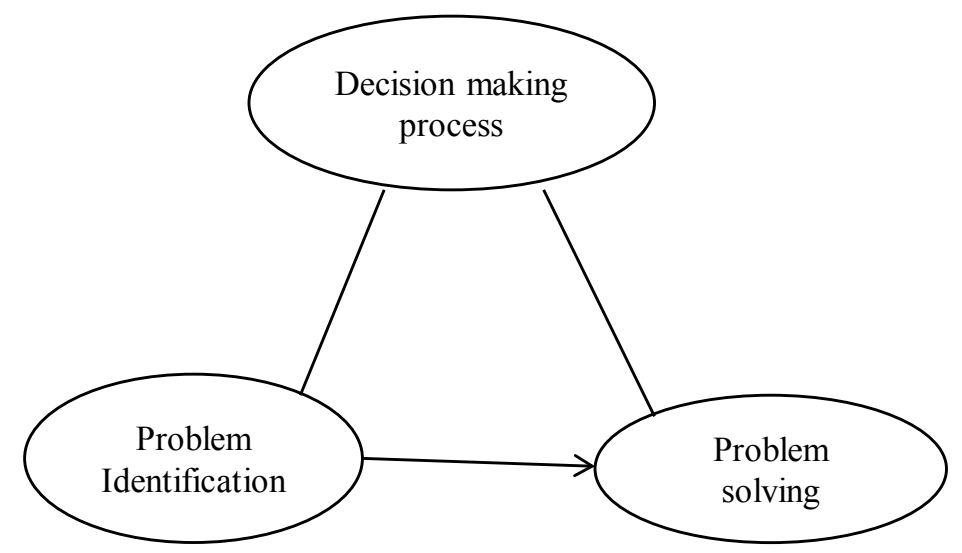

Figure 1. Model of decision making process. Source: Researchers Desk (2019).

through turbulent environment by decisions made by them. Decision making as an action has shaped organisations and it is very symbolic to conclude that life is the sums of all the choices made. In making these relevant choices and choosing alternation, it is important to go through the decision-making steps.

\subsubsection{Decision Making Steps}

Figure 2 explains steps to be followed in making adequate decisions.

Bagshaw [4], states that the decision-making steps can be explained further:

1) Monitor the Decision Environment: As a manager, it is important to observe and monitor the environment of decision making in order to plan with the information available both internally and externally.

2) Explain the decision problem: based on the observation, the manager would have been able to get explanations for certain occurrences and should be able to attribute deviations where necessary and then take action as the case implies.

3) Identify the decision aim: the expected performance outcome is identified and direction clear.

4) Determine the problem: This is a total view of the problem to know the cause and possible solution, it involves analysis of the situation, identification of the deviations to set out objectives.

5) Develop alternative solution: This is achieved though brainstorming or via personal observation and experience in development of alternative solutions.

6) Evaluate alternative solution: The alternative solutions which are courses of actions or strategies need to be evaluated as to identify the optimal solution. The choice among alternatives is the essence of decision making.

In addition to the steps, Bagshaw [4] added that the Decision-making steps involve three approaches, the rational approach, the bounded rationality approach and the intuitive approach.

\section{1) The Rational Decision Making Approach}

The steps in the rational approach in making a good decision are basically the same no matter the type of decision needed in solving an identified problem. It 


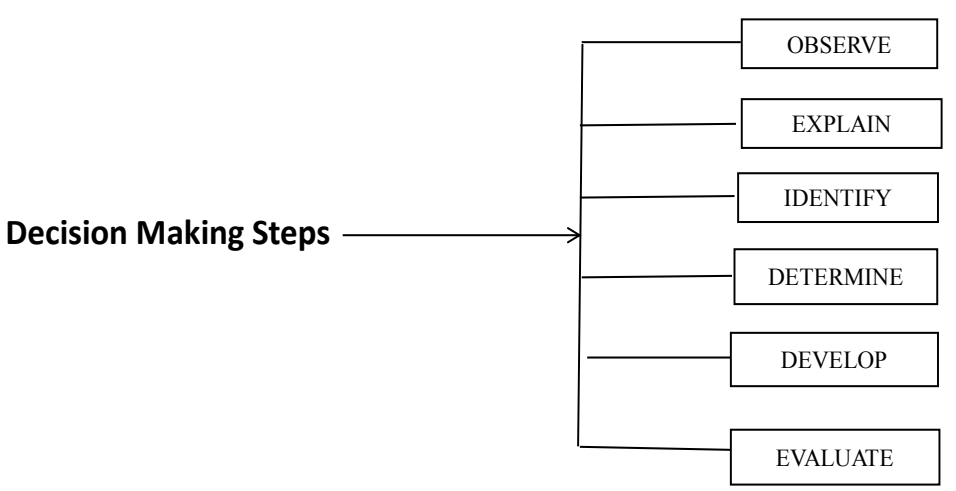

Figure 2. Decision making steps. Source: Researchers desk (2019).

has important equips the decision maker to establish decision criteria before you searching for alternatives so as to set criteria before picking an option. It is also important to set criteria before the search for alternatives this is to prevent making mistakes with choices. The rational model urges the decision maker to generate all alternatives instead of a selected few: when there is a pool of generated alternatives, positive decision making is possible from a wide range of choices. Decision-making model also involves a number of unrealistic assumptions. According to Bagshaw [4] observed that while the rational decision-making model may be a helpful tool for working through problems, it does not depict the frequency of decision making within the organisation.

\section{2) The Bounded Rationality Approach of Decision Making}

In today's competitive environment, with a high degree of a state of flux, it is almost impossible for managers to follow the systematic procedure outline in the rational approach. The attempt to be rational is bounded (limited) by the prevailing complexity of many problems [15]. It recognizes the limitations of our decision-making processes. According to this model, individuals knowingly limit their options to a manageable set and choose the best alternative without conducting an exhaustive search for alternatives. An important part of the bounded rationality approach is the tendency to satisfice, which refers to accepting the first alternative that meets your minimum criteria.

\section{3) The Intuitive Decision Making Approach}

The bounded rationality approach is followed by intuitive decision processes. Intuition is mostly appreciated where the manager had developed subconscious elements in solving problems based on long experience on work performance. It has emerged as an important decision-making model. It refers to arriving at decisions without conscious reasoning [17]. When we recognize that managers often need to make decisions under challenging circumstances with time pressures, constraints, a great deal of uncertainty, highly visible and high-stakes outcomes, and within changing conditions, it makes sense that they would not have the time to formally work through all the steps of the rational decision-making model. The intuitive decision-making model argues that, in a given situation, experts making decisions scan the environment for cues to recognize patterns [18] [19] [20] [21]. 


\section{Trends in Quantitative Analysis}

Quantitative analysis has evolved over time with highly sophisticated machine, Programmes, functions and tools that aid managerial decision making. Quantitative analysis is considered to have emerged during World War II with team of operation researchers seeking to find solution to strategic and tactical challenges the military faces [22] [23]. According to Anderson [24], challenge/problem was tackled via scientific methods in diverse fields such as the engineers, mathematicians, behavioural scientist. The trend today is a technology-powered quantitative analysis with a focus on machine learning, big data analytics, statistical package for social sciences (SPSS), spartial analysis, geocomputation, etc. Quantitative analysis trend is appreciated in research; methods of research and report following these trends. In addition to other quantitative function, globalisation, technological advancement and new drive for educational frontiers has given rise to recent patterns for which quantitative trends have become needful.

\section{Recent Trends in Quantitative Analysis}

1) Machine Learning: This is a subset of artificial intelligence (Industry 4.0) in the spheres of computer science. Machine learning is also statistically inclined using quantitative techniques to aid the computers with the ability to learn by progressively improve performance on a specific task and help to make end decisions. The name machine learning was first mentioned in 1959 by Arthur Samuel [25]. It evolves around patterns and computational learning theory in artificial intelligence, machine learning exploring the study and construct of algorithms that can learn from and make predictions on data such as algorithms to overcome the following static program instructions by making data-driven predictions or decisions, through building a model from sample inputs. Machine learning is employed in a range of computing tasks where designing and programming explicit algorithms with good performance is difficult or infeasible; example applications include email filtering, detection of network intruders or malicious insiders working towards a data breach, optical character recognition, learning to rank, and computer vision. Machine learning is closely related to (and often overlaps with) computational statistics, which also focuses on prediction-making through the use of computers. It has strong ties to mathematical optimization, which delivers methods, theory and application domains to the field Jordan [25]. Machine learning is sometimes conflated with data mining, where the latter subfield focuses more on exploratory data analysis and is known as unsupervised learning. Machine learning can also be unsupervised and be used to learn and establish baseline behavioural profiles for various entities and then used to find meaningful anomalies. Within the field of data analytics, machine learning is a method used to devise complex models and algorithms that lend themselves to prediction; in commercial use, this is known as predictive analytics. These analytical models allow researchers, data scientists, engineers, and analysts to produce reliable, repeatable decisions and results and uncover 
hidden insights through learning from historical relationships and trends in the data. Machine learning also has intimate ties to optimization, formulated problems are learned as minimization of loss function or maximisation of positive choice function.

2) Big Data Analytics: Statistically what is being analysed is a data. Today's IT world is focused on the big data with the rapid rise in the internet and coupled with the category of breed of employees in this 21 st century. The digitised economy is geared towards growth exponentially in proportion with the demand for data storage and analytics. It has also become a challenge to protect and analyse the volume of information generated and organisation depend on information gathering and storing [26]. Big data can be used to predict future volumes, gain insights and have provided precautionary measures of action for better decision making. Big data analytics is a way of extracting value from a pool of information to help the business world with respect to decision making. Big data analytics improve competitive advantage using a set of data algorithms especially for large data.

3) Statistical Package for Social Sciences (SPSS): is a powerful, user-friendly software package for the manipulation and statistical analysis of data. The package is useful for decision making by researchers, containing an extensive range of both univariate and multivariate procedures which is used for conclusion on decision to be carried out with respect to findings. Statistical analyses computed using the various versions of SPSS [27]. The Statistical Package for the Social Sciences (SPSS) is a package of programs for manipulating, analysing, and presenting data; the package is widely used in the social and behavioural sciences. According to Tarone [28], the core program of SPSS is based on a number of add-on modules that extend the range of data entry, statistical, or reporting capabilities. The most important of these analyses are the advanced models and regression models with add-on modules.

4) Spatial Analysis: Spatial analysis has several definitions to it, it has diverse and comprehensive capability covering simple visual analysis of maps and imagery, computational analysis of geographic patterns, finding optimum routes, site selection, and advanced predictive modeling. In spatial, attention is concentrated on understanding and establishing variety across space. This inclination in this particular direction comes with the concerns of Space Analytical methods and it repudiates the rather inexperienced criticism that quantitative geography is undeservedly associated with search for global generalities and laws.

- Issues here are associated with the development of statistical techniques purposed at local rather than the global.

- There is slight movement in prominence considering the increasingly ready large and complex spatial set of data.

Spatial analysis unfolds the overwhelming rise in the computational power and readily obtainable spatial data of a period. [29]

5) Geocomputation Analysis: Geocomputation is a technique that elaborates 
primary quantitative within geography to take advantage of increase in computer power and data [29] [30]. Geocomputation is computer aided quantitative analysis. The computer performs a crucial part in this technique. It is an emerging and fast-growing field of research that recommends the use of computational and intensive techniques such as neural networks, heuristic search, and cellular automata for spatial data analysis. Data is gathered from within a geographical region of reference, showing a potential increase of data for analysis. Geocomputation computerises data rich environments with an affordable computational power in spatial data analysis and mining techniques. The computerised database is with geographical referencing for census tract or postal code. It is also a set of algorithm-driven technique covering neurocomputation, fuzzy logic, and cellular automata. Geocomputation technique or analysis is explained in four different approaches e.g. computer intensive pattern search, exploratory spatial data analysis, artificial intelligence techniques, and dynamic modelling.

\section{Quantitative Analysis and Decision Making}

An essential managerial skill is the allocation and utilization of resources in an effort to effectively and efficiently achieve the optimal performance especially in cases of complexity and dynamism, decision is based on intuition with a quantitative base that is reasonably accepted and practiced in the achievement of organisational goal. It is pertinent for managers to enhance their decision-making competence through experiential and scientific knowledge acquisition [24]. This will ensure a seamless decision-making process, an effective communication mechanism and efficient use of resources by the organisation. Quantitative as a decision-making mechanism aids manager with viable and adequate tools in effectively and efficiently carrying out managerial functions. Quantitative techniques or analysis in the organisation identifies and records decision type that will influence the goals of the organisation. Managers may enhance decision making capabilities by learning more about quantitative methodologies and by better understanding their contributions to the decision-making process. A manager who is knowledgeable in quantitative decision making procedures is in a much better position to compare and evaluate the quantitative sources of information and, ultimately, to combine alternatives in making the best possible decisions. Decision making as a behavioural method is closely tied to quantitative techniques in solving organisational problems to yield optimum result [31]. Quantitative factors in decision making cover investment appraisal, break even analysis, market research, sales forecasting, critical path analysis, decision trees, chi square, correlation analysis, Regression analysis, Simulation, transportation analysis, network analysis, t-test, etc. Giving numerical base for decision making and by way of reducing decision regarding monetary value placed on different choices in forecasting sales figures for a period, impact of redundancies over time and these data affords only a fragment of the concept [4]. 


\section{Application of Trends in Quantitative Analysis on Decision Making}

The future of the organisation lies in the decision-making ability of the manager and beyond that the techniques involved in making a hitch free decision is also key. To this end, the application of trends in quantitative analysis on decision making is explained below:

\subsection{Machine Learning and Decision Making}

Machine Learning is a powerful tool that aids the adaptation and accelerates the decisions that are made in today's organisation. Decision-making systems can be built to walk without human interference but that will be effective with inventions of machine learning that are able to make decisions on its own as part of its design. It is imperative for organisations today to leverage on machine learning for predicting and determining causality [32].

\subsection{Big Data Analytics and Decision Making}

Information is a key factor in successfully influencing the decision making ability of any manager in making quality, accurate and bias decisions. Today's decision making amounts to the availability of data analysis for a smooth operation of the organisations; Decision is deduced from the analysed data. Data is appreciatively the latest input resource or material in this present time and age. Decision makers need to be able to gain valuable insights from such rapidly changing data of high volume, velocity, variety, veracity, and value by using big data analytics [33].

\subsection{Statistics Package for Social Sciences (SPSS) and Decision Making}

The world is changing rapidly: the environment of business causing a change in the organisation as well. This change carries opportunities and difficulties too. In such an environment or society, decision making becomes difficult and complicated. The decision maker is meant to look beyond and apply exact quantitative methods for decision support e.g. marketing research, analysing and using the data from marketing research, costs, revenues, profits, input, output modelling, simulation, quality control, etc. This variety of methods and techniques is usually supported by software usage, with user-friendly graphical design. One of the appropriate software for decision making support is SPSS. It is a useful tool for sustaining competitive advantage [34].

\subsection{Spatial Analysis and Decision Making}

Decision making is either rationally or irrationally and spatial analysis as a quantitative tool can be employed by the decision maker in making thorough decision by visualising the problem, defining relationships between factors, predicting outcomes through modelling, evaluating how sensitive decisions are to 
changes in individual factors and finally visualising the spatial relationships between potential factors [35]

\subsection{Geocomputation and Decision Making}

Geocomputation can be linked with spatial analysis to an extent. geographical data that is generated via the geographical information system is useful in carrying spatial analysis. These data are needful in making decisions. Geocomputation is part of the information system field and it is a computer program application that analyses business data, present such data for decision making in an organisation. It is designed to assist the planner with a guide in making decision especially on land use e.g. organisation sites, airport, etc. and this is made possible with the creation of model to help identify the most effective decision path [36].

\section{Conclusion}

Decision making involves solving a problem known as decision problem for which decision has to be taken resulting in a set of alternative actions and quantitative analysis is a tool that aids corporate decision making and also in individual decision making as well [37]. The decisions made from the alternative are implemented and monitored as to have a feedback mechanism in control of the system and at every point in the system, information is needful to be fully loaded with the knowledge required to make a decision, the conditions and then the environment for such decision.

\section{Conflicts of Interest}

The authors declare no conflicts of interest regarding the publication of this paper.

\section{References}

[1] Ehlers, T. and Lazenby, K. (2007) Strategic Management: Southern African Concept and Cases. Van Schaik Publishers, Pretoria.

[2] Dunn, W.N. (1994) Public Policy Analysis: An Introduction. Prentice Hall, Upper Saddle River.

[3] Valero, C.A. (1997) Applications of Qualitative and Quantitative Techniques of Management in Administrative/Academic Decision Making in Institutions of Higher Education in Virginia. Dissertation Submitted to the Faculty of the Virginia Polytechnic Institute and State University, Blacksburg.

[4] Bagshaw, K.B. (2017) Process and Product Design: Production Efficiency of Manufacturing Firms in Rivers State, Nigeria. Engineering Management Research, 6, 49-55. https://doi.org/10.5539/emr.v6n1p49

[5] Edmonds, J. and Giles, R. (1977) A Min-Max Relation for Submodular Functions on Graphs. Studies in Integer Programming. Annals of Discrete Mathematics, 1, 185-204. https://doi.org/10.1016/S0167-5060(08)70734-9

[6] Dantzig, G.B. (1947) Maximization of a Linear Function of Variables Subject to 
Linear Inequalities. In: Koopmans, T.C., Ed., Activity Analysis of Production and Allocation, Wiley \& Chapman-Hall, New York, London, 339-347.

[7] Donald, W. (2013) Inventory Control and Management. 2nd Edition, John Wiley India Pvt. Limited, Hoboken.

[8] Sundarapandian, V. (2009) "7 Queuing Theory", Probability, Statistics and Queuing Theory. PHI Learning, New Delhi.

[9] Mac'Ódo, D.S. (1999) Statistics for Decision Making. Linnet Paul Publishers, Port Harcourt.

[10] Prasad, L.M. (2004) Principles and Practices of Management. Sultan Chand, New Delhi.

[11] Miller, C.C. and Ireland, R.D. (2005) Intuition in Strategic Decision Making: Friend or Foe in the Fast-Paced 21st Century? Academy of Management Executive, 19, 19-30. https://doi.org/10.5465/ame.2005.15841948

[12] Nutt, P.C. (1998) Surprising But True: Half the Decisions in Organizations Fail. Academy of Management Executive, 13, 75-90. https://doi.org/10.5465/ame.1999.2570556

[13] Nutt, P.C. (2002) Why Decisions Fail. Berrett-Koehler, San Francisco.

[14] Mann, D. (1976) Policy Decision-Making in Education. Teachers College Press, New York.

[15] Daft, R.L. (1998) Organization Theory and Design. South-Western College Publishing, Cincinnati.

[16] Daft, R.L. (1999) Leadership. The Dryden Press, Fort Worth.

[17] Burke, L.A. and Miller, M.K. (1999) Taking the Mystery out of Intuitive Decision Making. Academy of Management Executive, 13, 91-98. https://doi.org/10.5465/ame.1999.2570557

[18] Betsch, C. (2008) Chronic Preferences for Intuition and Deliberation in Decision Making: Lessons Learned about Intuition from an Individual Differences Approach. In: Plessner, H., Betsch, C. and Betsch, T., Eds., Intuition in Judgment and Decision Making, Lawrence Erlbaum, Mahwah, 231-248.

[19] Salas, E. and Klein, G. (2001) Linking Expertise and Naturalistic Decision Making. Lawrence Erlbaum, Mahwah. https://doi.org/10.4324/9781410604200

[20] Klein, G. (2001) Linking Expertise and Naturalistic Decision Making. Lawrence Erlbaum, Mahwah.

[21] Keith, N. and Frese, M. (2008) Effectiveness of Error Management Training: A Meta-Analysis. Journal of Applied Psychology, 93, 59-69. https://doi.org/10.1037/0021-9010.93.1.59

[22] Ukpere, W.I. (2010) Capitalist Globalisation in Limbo. Lambert Academic Publishers, Saarbrücken.

[23] Unicef (n.d.) Quantitative and Qualitative Methods: Compared and Mixed. https://www.unicef-irc.org/publications/pdf/iwp_2009_05.pdf

[24] Anderson, D., Sweeney, D. and Williams, T. (1994) An Introduction to Management Science: Quantitative Approaches to Decision Making. South Western Publishing Co., Mason.

[25] Jordan, K.E. (2014) Decision Making in Choosing Information System. Journal of Information and Knowledge Management Science, 44, 162-180. https://doi.org/10.1108/VINE-04-2013-0022

[26] Dhawan, S. and Rathee, S. (2013) Big Data Analytics Using Hadoop Components 
like Pig and Hive. American International Journal of Research in Science, Technology, Engineering \& Mathematics, 2, 88-93.

[27] Stevens, J. (1992) Applied Multivariate Statistics for the Social Sciences. Erlbaum, Hillsdale.

[28] Tarone, R.E. and Ware, J. (1977) On Distribution Free Tests for Equality of Survival Distributions. Biometrika, 64, 156-160. https://doi.org/10.1093/biomet/64.1.156

[29] Openshaw, S. (1994) Two Exploratory Space-Time-Attribute Pattern Analysers Relevant to GIS. In: Fotheringham, A.S. and Rogerson, P., Eds., Spatial Analysis and GIS, Taylor and Francis, London, 83-104. https://doi.org/10.4324/9780203221563_chapter_Two

[30] Openshaw, S. (1995) Developing Automated and Smart Spatial Pattern Exploration Tools for Geographical Systems Applications. The Statistician, 44, 3-16. https://doi.org/10.2307/2348611

[31] Foxley, C. (1980) Determinants of Managerial Effectiveness. New Directions for Student Services, 1980, 1-9. https://doi.org/10.1002/ss.37119800903

[32] Elgendy, N. and Elragal, A. (2014) Big Data Analytics: A Literature Review Paper. In: Advances in Data Mining: Applications and Theoretical Aspects, Springer International Publishing, Berlin, 214-227. https://doi.org/10.1007/978-3-319-08976-8_16

[33] Chang, R.M., Kauffman, R.J. and Kwon, Y. (2014) Understanding the Paradigm Shift to Computational Social Science in the Presence of Big Data. Decision Support Systems, 63, 67-80. https://doi.org/10.1016/j.dss.2013.08.008

[34] Oakland, S. and John, S. (2003) Statistical Process Control. Butterworth Heinemann, Oxford, 445.

[35] Heywood, I., et al. (1995) Building an Exploratory Multi-Criteria Modelling Environment for Spatial Decision Support. In: Fisher, P., Ed., Innovations in GIS 2, Taylor and Francis, London, 127-136.

[36] Parker, D.C., Manson, S.M., Janssen, M.A., Hoffmann, M. and Deadman, P. (2003) Multi-Agent Systems for the Simulation of Land-Use and Land-Cover Change: A Review. Annals of the Association of American Geographers, 93, 314-337. https://doi.org/10.1111/1467-8306.9302004

[37] Agrawal, S., Subramanian, S.K. and Kapoor, S. (2010) Operations Research Contemporary Role in Managerial Decision Making. International Journal of Resource Review in Applied Science, 3, 200-208. 